\title{
Western monopoly of climate science is creating an eco-deficit culture
}

A recent study showed that 78\% of global climate science funding flows to European and North American institutions. Dr. Quan-Hoang Vuong gives his perspective on why this is a problem for the planet.

BY QUAN-HOANG VUONG NOVEMBER 11, 2021 


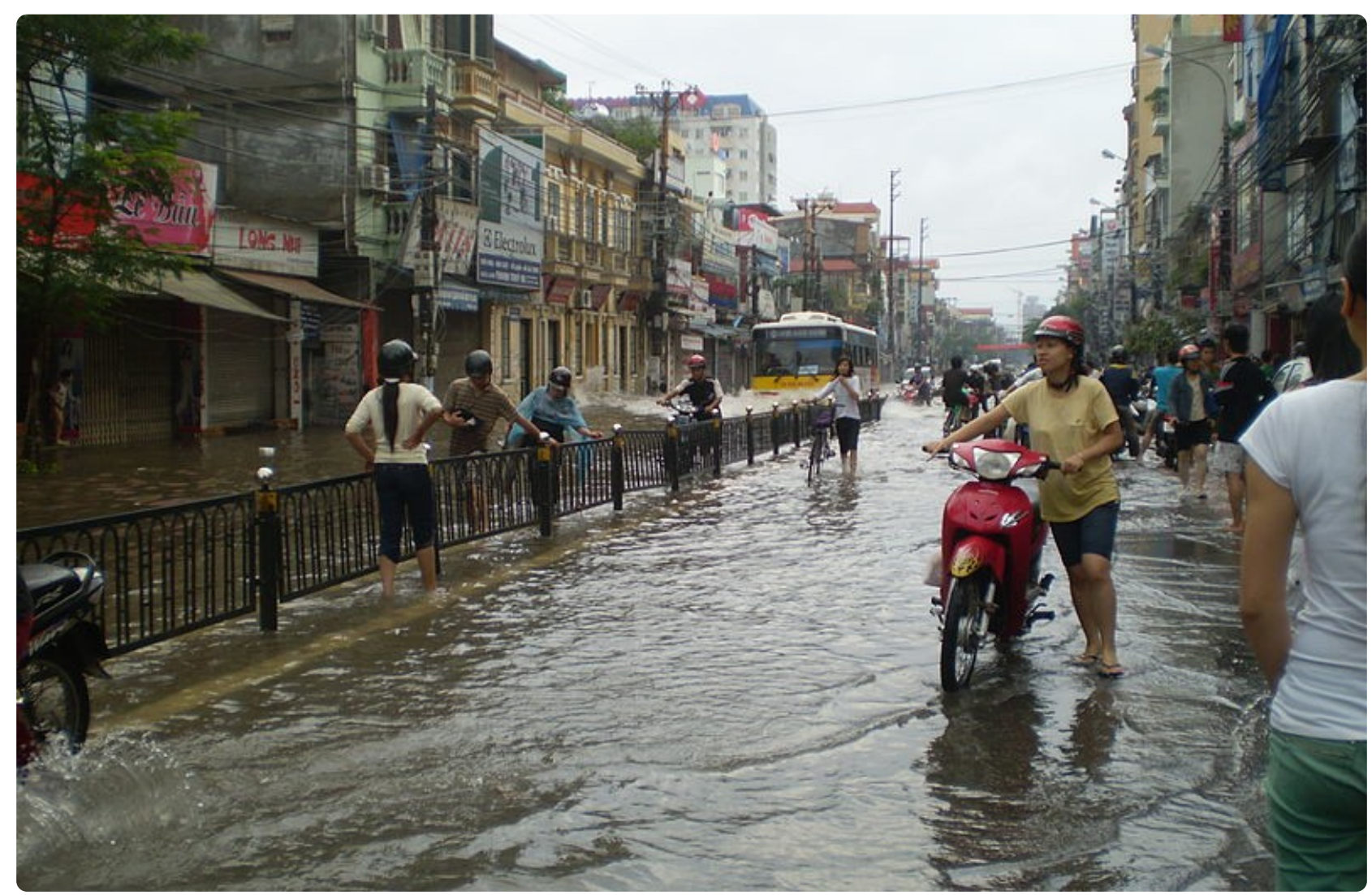

\section{Europe and America are monopolising climate science}

$\mathrm{I}$

n 2020, the world buckled underneath the COVID-19 pandemic. But in Vietnam, as in many of the countries worst affected by climate change, COVID was not the only difficulty they saw that year. The country suffered from catastrophic floods in its central region provinces. At least 243 people were reported dead (https://reliefweb.int/report/viet-nam/vietnam-floodsemergency-appeal-n-mdrvn020-operation-update-n-1-1-december-2020), and the damage was estimated at around US\$1.5 billion. While climate scientists were able to predict the typhoon and set mitigatory measures in motion, the storms and landslides destroyed a hydropower plant's construction site and buried thirteen rescue volunteers (https://abcnews.go.com/International/wireStory 
/bodies-13-rescuers-recovered-vietnam-landslide-73649551). The desolation was a blow to the nation. Vietnam's long coastline has long left us exposed to such storms. We understand the potential for destruction, so every year, we prepare for typhoon season. However, the warming ocean water has fuelled the typhoons, allowing the intensification rate to increase by around 12 to $15 \%$ (https://www.nature.com/articles/ngeo2792?proof=t\%29.). Meanwhile, Vietnam's technologies struggle to mitigate against their worst effects.

Too often during international climate negotiations such as COP26, the effects of climate change are framed by richer countries in the Global North as something that will happen; they are imagined in the future tense. Meanwhile, countries such as Vietnam are facing stronger typhoons happening now and throughout each year. No matter how proactive we are in preparation, typhoons are still devastating, destroying homes and destroying lives. Meanwhile, with enormous resources, Western countries predict how climate change will affect The West, and prepare for mitigating these outcomes in The West. Countries such as the USA and UK have long held a leading global position, from which, when it is perceived as affordable, they assist lesser developed nations. The monopoly of Western climate science does not allow for adequate research into practical measures to help developing countries fight against the present realities of climate change.

In a recent Carbon Brief article (https://www.carbonbrief.org/analysis-the-mostcited-climate-change-papers), Ayesha Tandon found that only 7.3\% of more than 1300 authors from the top 100 most-cited climate papers are from Asia. None of those authors were Vietnamese. When Ayesha showed me her findings and asked for my opinions, I was indifferent. The number was not surprising. Whether we want to admit it or not, the representatives of climate science expertise are mostly from more developed countries. Advanced infrastructure and abundant resources have helped the West to establish its authority over climate issues. Developing countries will often send their best and brightest to receive education from more developed countries, as top experts need both training and global recognition to gather resources to deal with climate change. While training gaps can be 
addressed by academic migration, scientists from lesser developed countries rarely receive global recognition.

A new article in Climate and Development (https://www.tandfonline.com/doi/full $/ 10.1080$

/17565529.2021.1976609?utm_campaign=Carbon\%20Brief\%20Daily\%20Briefing\& utm_content=20210927\&utm_medium=email\&utm_source=Revue\%20Daily) showed that $78 \%$ of the global climate science funding in the 1990-2020 period flowed to European and North American institutions. However, only 3.8\% of the funding was spent on Africa-related topics. This is despite the fact that Africa is the continent most vulnerable to climate change (https://theconversation.com /climate-change-is-a-justice-issue-these-6-charts-show-why-170072), and the continent that has contributed the lowest proportion of historic greenhouse gas emissions: only 3\%. Globally, the Global Landscape of Climate Finance 2021 (https://www.climatepolicyinitiative.org/wp-content/uploads/2021/10/GlobalLandscape-of-Climate-Finance-2021.pdf) reported a concentration of climate finance in Europe, North America, and East Asia and Pacific regions. However, the report showed that around $73 \%$ of the global climate finance (roughly US $\$ 479$ billion) was funded domestically, which indicated that most countries still rely on themselves to fight climate change. Meanwhile, international climate finance increased from US\$13 billion in the 2017-2018 period to US\$153 billion. However, as the money was spread between many countries, the eventual resources were not significant enough.

In late 2019, my colleagues and I encountered the 'trilemma of sustainable industrial growth' (https://www.nature.com/articles/s41599-019-0369-8) in Kitakyushu, Japan - one of the leading green-growth-oriented cities worldwide. Kitakyushu's response to environmental issues is similar to those seen in Western Europe: advanced technological infrastructure, political interventions, and the employ of top experts. Despite the stringent green growth regulation context and extensive advanced technology use, many air pollution problems could not be solved due to socio-cultural factors: urban sprawl, rising travel demand, large firms outsourcing production to smaller firms without rigorous inspection and 
enforcement of emissions criteria. The example of Kitakyushu raises the importance of understanding private sectors' and residents' cultures in promoting green development. It indicates that the replication of the Western model might still not be effective in Eastern locales.

\section{Non-Western science not being platformed leads to an 'eco-deficit culture'}

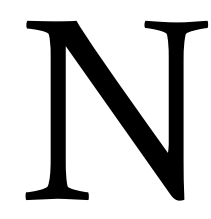

ot only does Kitakyushu show why Western models are not always applicable globally, it shows how cultural attitudes to climate change can vary, even in locations where people are faced with its increased and more immediate risks.

My country, Vietnam, prides itself on its rich biodiversity. Yet, in 2015, I saw a family of sparrows drinking from a tank of air conditioner wastewater for their survival. It was disheartening to see the sparrows drinking water so desperately. How could this happen in a country so rich in natural resources? This family of sparrows are in many ways like the Vietnamese people. We have suffered from terrible climate conditions, and our society does not prioritise nature or the environment. This "eco-deficit culture", which prioritises paying lower costs than the actual price of environmental damage (https://philarchive.org/archive /VUOTSP), shows why we need to promote the voices of Non-Western climate scientists. Without our research being funded and boosted, our values suffer as well as our science.

Such cultural values are ingrained at a young age, across society. In another study (https://arxiv.org/ftp/arxiv/papers/2006/2006.09706.pdf), we shifted our observations to video game players and their environmental relationship with games. In the particular case of the life-simulation game 'Animal Crossing: New Horizons', we found that the game players' behaviour in the virtual world eventually converged into a similar mode: exploiting resources to complete the mission. This may be more explained by in-game behaviours being coded into the game design than by game players' attitudes - but either way, this has cultural significance. As cultural producers with great potential to influence younger 
generations, games companies can do better to educate and engage game players in pro-environmental manners.

\section{This eco-deficit culture slows down private sector intervention}

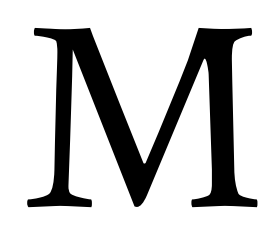

ost importantly, however, this deficit of cultural and scientific influence on climate issues affects how the business sector operates.

As a person who spent years in the business sector before moving to academia, I recognised that a possible pathway for developing countries to escape the dilemma between economic growth and environmental degradation is harnessing the power of the business sector. Currently, private sectors have only contributed US\$37 billion to climate finance in South America, Africa, and South Asia areas, compared with US\$ 63 billion from the public sector. The business sector has great resources to lobby for policy change. Their interests lie in profits. My recent investigation of 75 news-reported environmental events in Vietnam (https://onlinelibrary.wiley.com/doi/abs/10.1002/csr.2029) suggests a bleak picture of corporate responsibility when it comes to protecting the environment. Sectors that capitalise on natural resources, like forestry, hydropower, thermopower, or even environment industries, were involved in many environmentally damaging events. For instance, in 2017, a canal named Ba Bò in Vietnam was heavily polluted (https://onlinelibrary.wiley.com/doi/epdf/10.1002 /csr.2029) due to wastewater from a nearby wastewater treatment plant.

We still need to change, we still need better effort, and we still need to save the planet. To do all of this, we need to listen to and encourage scientific research from everywhere around the world, and we need more from business. I have previously suggested a new way to calculate a business's net profit (https://philarchive.org/archive/VUOTSP) by incorporating the value of the environment in the equation. Directly challenging the framework of business' profits will make the necessary changes for a better future. And for businesses to act meaningfully, we need to listen to academics from everywhere in the world on what approaches will work. 
Tremendous efforts not just from the hard sciences and experts in the Global North but also social sciences and experts in the Global South will be required to make us ready for such a long and hard war. Like the sage Hillel the Elder famously put it some two thousand years ago:

"If not me, who? If not now, when?"

\section{Further reading}

(2020). 21 killed, dozens missing after Typhoon Molave lashes Vietnam. Al Jazeera. Read here (https://www.aljazeera.com/news/2020/10/29/13-killeddozens-missing-after-typhoon-molave-lashes-vietnam).

Nilsen T. (2021). Norway offers oil firms 70 new Barents Sea exploration blocks. The Barents Observer. Read here (https://thebarentsobserver.com/en/industryand-energy/2021/06/norway-offers-oil-firms-70-new-barents-sea-explorationblocks).

Tandon A. (2021). Analysis: The lack of diversity in climate-science research. Carbon Brief. Read here (https://www.carbonbrief.org/analysis-the-lack-ofdiversity-in-climate-science-research).

Vuong QH, Ho MT, Nguyen HKT, Nguyen MH. (2019). 'The trilemma of sustainable industrial growth: Evidence from a piloting OECD's Green city'. Palgrave Communications, 5, 156. Read here (https://www.nature.com/articles /s41599-019-0369-8).

Vuong QH, La VP, Nguyen THK, Ho MT, Vuong TT, Ho MT. (2021).

'Identifying the moral-practical gaps in corporate social responsibility missions of Vietnamese firms: an event-based analysis of sustainability feasibility'. Corporate Social Responsibility and Environmental Management, 28(1), 30-41. Read here (https://onlinelibrary.wiley.com/doi/abs/10.1002/csr.2029).

Vuong QH, Ho MT, Nguyen MH, Pham TH, Vuong TT, Khuc QV, Ho HA, La 
VP. (2021). 'On the environment-destructive probabilistic trends: a perceptual and behavioral study on video game players'. Technology in Society, 65, 101530. Read here.

Vuong QH. (2020). ‘From children's literature to sustainability science, and young scientists for a more sustainable Earth'. Journal of Sustainability Education, 24(3), 1-12. Read here (http://www.susted.com/wordpress/content/from-childrensliterature-to-sustainability-science-and-young-scientists-for-a-more-sustainableearth_2020_12/).

Vuong QH. (2021). 'The semiconducting principle of monetary and environmental values exchange’. Economics and Business Letters, 9(3), 284-290. Read here (https://philarchive.org/archive/VUOTSP).

Quan-Hoang Vuong is Director of the Centre for Interdisciplinary Social Research, Phenikaa University in Hanoi, Vietnam. He is a Distinguished Associate for The Vietnam Institute for Advanced Study in Mathematics, Chairman of the Vietnam chapter of the European Association of Science Editors and serves in the NAFOSTED Scientific Council on Basic Research. You can email him here (mailto:hoang.vuongquan@phenikaauni.edu.vn).

Share this article...

$\boldsymbol{y}$ in 